\title{
Esclerose Sistémica Juvenil
}

\author{
Juvenile Systemic Sclerosis
}

Marta LOUREIRO ${ }^{1}$, Sandra SOUSA ${ }^{2}$, Maria José SANTOS ${ }^{2}$

Acta Med Port 2015 Nov-Dec;28(6):785-785

Palavras-chave: Criança; Escleroderma Sistémica.

Keywords: Child; Scleroderma, Systemic.

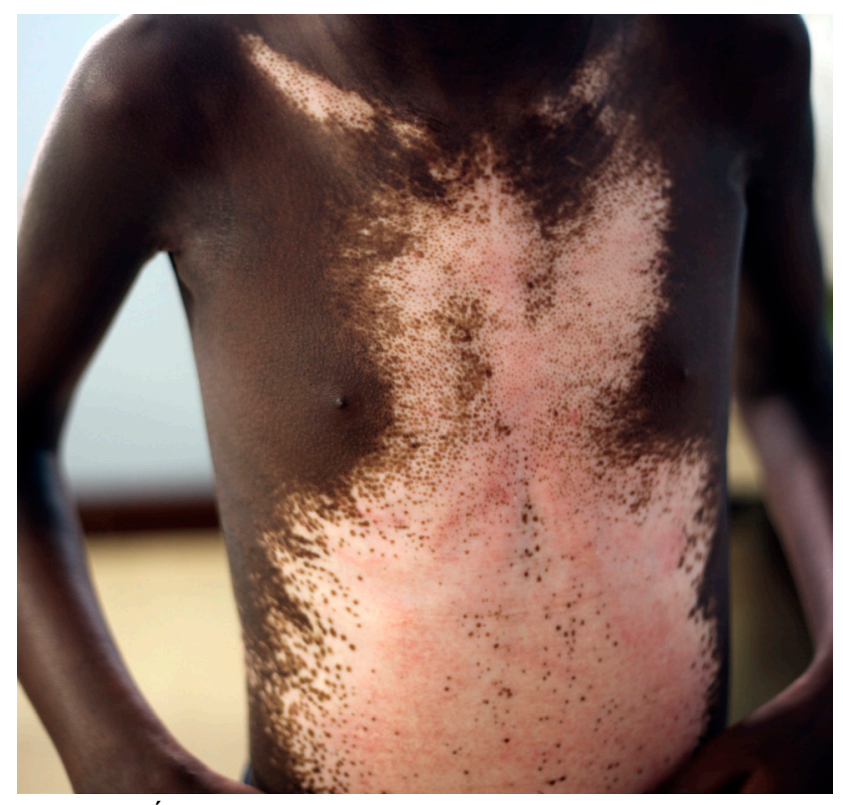

Figura 1 - Áreas de despigmentação e hiperpigmentação da pele em 'sal e pimenta', conferindo um aspecto de 'pseudo-vitiligo' uma das manifestações cutâneas da esclerose sistémica

Criança de sete anos, sexo feminino, observada em consulta por quadro com quatro meses de evolução de espessamento cutâneo difuso do tronco e membros, cansaço, poliartralgia e acrocianose. Apresentava anticorpos antinucleares (> 1/1 280) e anti-Scl70 positivos, elevação das enzimas musculares, padrão restritivo ligeiro da função respiratória, ecocardiograma com disfunção diastólica restritiva e trânsito esofágico sem alterações. Admitindo-se o diagnóstico de esclerose sistémica juvenil (ESJ), iniciou tratamento com prednisolona e metotrexato. Ao longo dos 18 meses de seguimento registou-se melhoria do espessa-

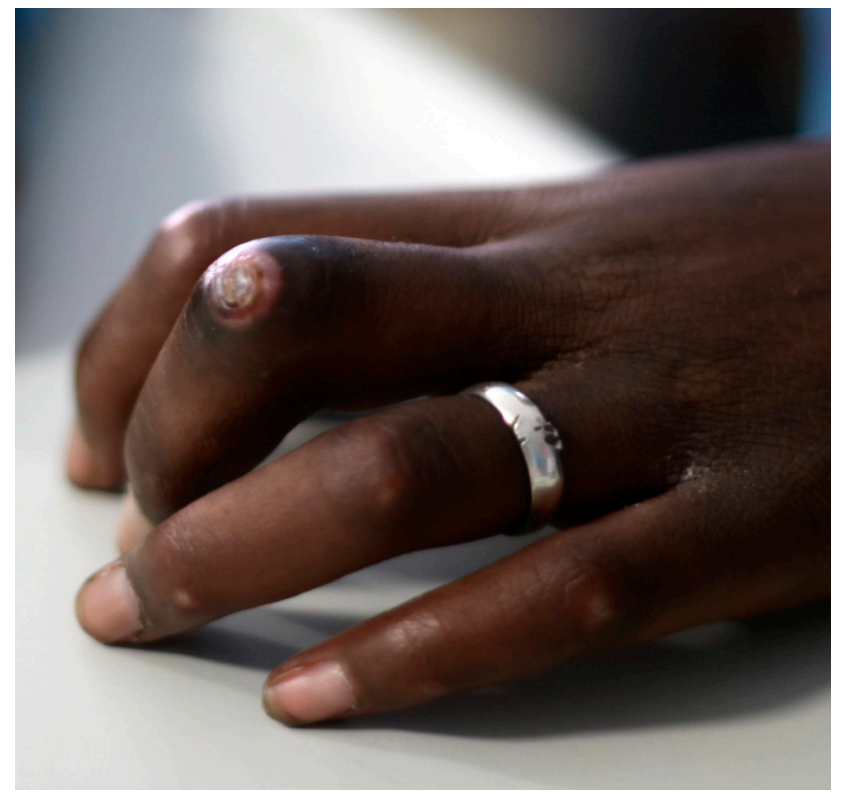

Figura 2 - Úlceras digitais com atingimento predominante das articulações interfalângicas proximais

mento cutâneo, evoluindo para áreas de despigmentação cutânea em 'sal e pimenta' (Fig. 1), e aparecimento de úlceras digitais (Fig. 2). Actualmente medicada com metotrexato subcutâneo, metilprednisolona e bosentan.

A ESJ tem uma incidência de 0,27 casos por milhão de crianças ${ }^{1}$ e apresenta particularidades que a distinguem das formas adultas de esclerose sistémica. ${ }^{2} \mathrm{~A}$ abordagem terapêutica em idade pediátrica, actualmente extrapolada de ensaios em adultos, é um desafio, reforçando a necessidade de estudos em crianças. ${ }^{3}$

\section{REFERÊNCIAS}

1. Herrick AL, Ennis H, Bhushan M, Silman AJ, Baildam EM. Incidence of childhood linear scleroderma and systemic sclerosis in the UK and Ireland. Arthritis Care Res. 2010;62:213-8.

2. Denton CP, Derrett-Smith EC. Juvenile-onset systemic sclerosis: children are not small adults. Rheumatology. 2009;48:96-7.

3. Foeldvari I. Update on juvenile systemic sclerosis. Curr Rheumatol Rep. 2015;17:491.

\footnotetext{
1. Serviço de Pediatria. Hospital Garcia de Orta. Almada. Portugal.

2. Serviço de Reumatologia. Hospital Garcia de Orta. Almada. Portugal.

$\triangle$ Autor correspondente: Marta Loureiro. martafloureiro@gmail.com

Recebido: 11 de Abril de 2015 - Aceite: 21 de Julho de 2015 | Copyright @ Ordem dos Médicos 2015
} 


\section{Esclerose Sistémica Juvenil}

Acta Med Port 2015:28:785-785

Publicado pela Acta Médica Portuguesa, a Revista Científica da Ordem dos Médicos

Av. Almirante Gago Coutinho, 151

1749-084 Lisboa, Portugal.

Tel: +351218428215

E-mail: submissao@actamedicaportuguesa.com

www.actamedicaportuguesa.com

ISSN:0870-399X | e-ISSN: 1646-0758

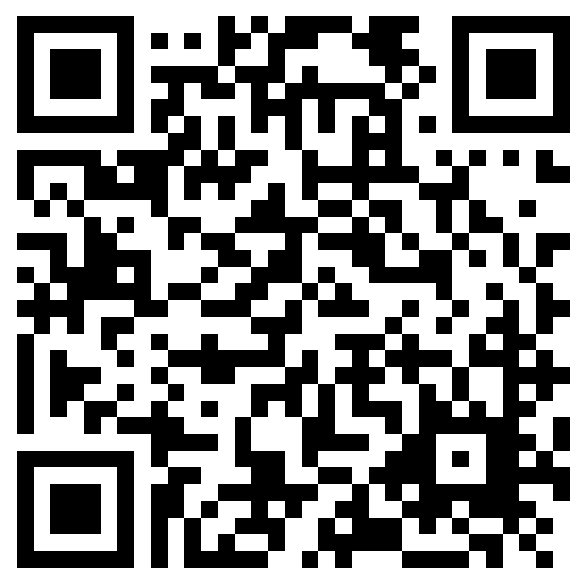

